\title{
Prophylactic noninvasive positive pressure ventilation in the weaning of difficult-weaning tracheotomy patients
}

\author{
Guo-Peng Liang ${ }^{1}$, Yi-Hua Zeng ${ }^{2}$, Bai-Xu Chen ${ }^{1}$, Yan Kang ${ }^{1}$ \\ ${ }^{1}$ Department of Critical Care Medicine, ${ }^{2}$ Department of Respiratory Critical Care Medicine, West China School of Medicine and West China \\ Hospital, Sichuan University, Chengdu 610041, China \\ Contributions: (I) Conception and design: GP Liang, Y Kang; (II) Administrative support: Y Kang; (III) Provision of study materials or patients: Y \\ Kang; (IV) Collection and assembly of data: GP Liang, YH Zeng, BX Chen; (V) Data analysis and interpretation: GP Liang, YH Zeng, Y Kang; (VI) \\ Manuscript writing: All authors; (VII) Final approval of manuscript: All authors. \\ Correspondence to: Yan Kang, MM. Department of Critical Care Medicine, West China Hospital, Sichuan University, Chengdu 610041, China. \\ Email: kangyan@scu.edu.cn.
}

\begin{abstract}
Background: Prophylactic noninvasive positive pressure ventilation (NPPV) reduces reintubation in endotracheal intubation patients. However, the efficacy of using the prophylactic NPPV in the weaning of tracheotomy patients is unclear.
\end{abstract}

Methods: We performed prophylactic NPPV in 11 tracheotomy patients who passed a spontaneous breathing trial (SBT), removed the tracheotomy tube, and closed the incision (intervention group). We matched another 11 tracheotomy patients who also passed an SBT but weaning and removing of tracheotomy tube were managed as conventional methods (control group).

Results: Patients in the control group had reinstitution of mechanical ventilation 36 times after the initial SBT success. Compared with the control group, the interventional group had fewer weaning days $(3.0 \pm 2.1$ vs. $11.3 \pm 9.2, \mathrm{P}=0.01$ ) from initial SBT success to successful weaning and shorter intensive care unit (ICU) length of stay $(11.6 \pm 4.2$ vs. $20.3 \pm 11.6, \mathrm{P}=0.03)$ after initial SBT success. The interventional group had lower nosocomial pneumonia rates after initial SBT success (0/11 vs. 2/11), lower ICU mortality (0/11 vs. 2/11), lower hospital mortality (0/11 vs. 3/11), and higher successful weaning rate (11/11 vs. 8/11), but it didn't reach significant difference. Also, there was no significant difference between groups in total duration of ventilation $(25.5 \pm 13.3$ vs. $34.7 \pm 24.2$ days $)$, hospital stay after initial SBT success $(24.0 \pm 22.3$ vs. $37.4 \pm 31.3$ days), total ICU stay ( $35.7 \pm 15.3$ vs. $45.0 \pm 29.5$ days), and total hospital stay $(48.7 \pm 33.1$ vs. $68.6 \pm 52.6$ days).

Conclusions: Prophylactic NPPV may be useful to accelerate weaning, and shorten ICU stay after initial SBT success in tracheotomy patients.

Keywords: Mechanical ventilation; noninvasive positive pressure ventilation (NPPV); tracheotomy; weaning

Submitted Mar 01, 2019. Accepted for publication Jul 03, 2019.

doi: 10.21037/atm.2020.02.150

View this article at: http://dx.doi.org/10.21037/atm.2020.02.150

\section{Introduction}

Mechanical ventilation is one of the main treatment methods or temporary aids for the treatment of critically ill patients. However, the ultimate goal of mechanical ventilation is weaning from ventilators (1). Thus, weaning is the essential key point in the treatment of patients, including disconnecting from the ventilator and extubation (2).
Many intensive care unit (ICU) patients receiving mechanical ventilation because of their critical diseases, nutrition dysfunction, poor airway clearance ability, repeated lung infections, poor resistance to anti-infection and other factors of repeated respiratory failure. All of the above reasons would prolong mechanical ventilation, increase the rate of ventilator-associated pneumonia and mortality. Reintubation because of weaning failure is also 
an independent risk factor for increased mortality (3). Therefore, clinical physicians face a big challenge to improve weaning process and reduce reintubation (4).

Prophylactic noninvasive positive pressure ventilation (NPPV) shows many benefits in patients who pass a spontaneous breathing trial (SBT), including the decrease in reintubation and mortality (5-7). However, this weaning strategy mainly used in endotracheal intubation patients. Thus, the aim of this study was to explore the efficacy of prophylactic NPPV in the weaning process of tracheotomy patients.

\section{Methods}

This study was a prospective intervention and retrospective matched study. Our institutional review board (West China Hospital, Sichuan University) approved this study (No. 2016-0023). The patients in our ICU were managed as per our hospital protocol. The parameters of the ventilator were adjusted according to tidal volume, minute ventilation, respiratory rate (RR), blood gas analysis results, and the patients' tolerance. Daily routine assessment of the readiness for an SBT was performed every morning. The SBT was performed if the patient reached adequate oxygenation [arterial blood oxygen partial pressure $\left(\mathrm{PaO}_{2}\right) / \mathrm{FiO}_{2} \geq 150$, positive end-expiratory pressure (PEEP) $\left.\leq 5 \mathrm{cmH}_{2} \mathrm{O}\right]$, temperature $\leq$ $38^{\circ} \mathrm{C}, \mathrm{RR} \leq 30$ breaths/min, heart rate (HR) $\leq 120$ beats $/ \mathrm{min}$, and hemodynamic stability. The failure of SBT was defined as the presence of any of the following, $\mathrm{SpO}_{2}<90 \%$ or $\mathrm{PaO}_{2}$ $<60 \mathrm{mmHg}$ with $\mathrm{FiO}_{2} \geq 50 \%, \mathrm{pH}<7.32, \mathrm{PaCO}_{2}$ increases $10 \mathrm{mmHg}$ or higher, HR $>140$ beats/min or change $20 \%$ or more, systolic blood pressure $<90$ or $>180 \mathrm{mmHg}$, or increase $20 \%$ or more, RR $>35$ breaths/min or change $50 \%$ or more, subjective feeling unwell obviously, and significant worsen in mental state, such as drowsiness, coma, restlessness or anxiety. After SBT failure, patients were received comfortable ventilation support, and the weaning assessment continued the next day. The reasons for tracheotomy in enrolled patients were facilitation of weaning, convenience for oral care and decreased ventilator-associated pneumonia. Usually, tracheotomy was performed between 7 to 14 days of intubation. However, it was determined by the attending physician's discretion. The conditions of the sputum and airway patency were recorded by the nurse every day as our hospital protocol.

\section{Interventional group}

The prospective intervention group was based on 11 recruited patients between May 2016 and Jan 2017 in our
ICU. At enrollment, written informed consent was received from the patients or their next of kin.

Inclusion criteria were as follows: (I) difficult weaning defined as the patients failed at least one SBT (8), (II) tracheotomy tube in place, and (III) successful completion of an SBT. Exclusion criteria were as follows: (I) under 18 years of age, (II) Glasgow Coma Scale (GCS) less than 12, (III) sputum abundant and sticky, (IV) weak cough, (V) patients with upper airway obstruction, (VI) craniofacial trauma or burns, (VII) high risk of aspiration, and (VIII) neuromuscular diseases.

A tracheotomy patient who successfully completed an SBT was enrolled. After enrollment, the tracheotomy tube was removed, and the incision was closed. And then, NPPV (BiPAP Vision or Respironics V60) was immediately used with a nasal or face mask.

NPPV was managed as follows. S/T model was used for all patients. Expiratory positive airway pressure was set to 4-6 $\mathrm{cmH}_{2} \mathrm{O}$ for hypercapnia patients, and $8-10 \mathrm{cmH}_{2} \mathrm{O}$ for hypoxemic patients. Inspiratory positive airway pressure was initially set to $10 \mathrm{cmH}_{2} \mathrm{O}$ and titrated to reach the tidal volume around $8-10 \mathrm{~mL} / \mathrm{kg}$. The fraction of inspiratory oxygen was titrated to maintain the $\mathrm{SpO}_{2}$ around $95 \%$ or $\mathrm{PaO}_{2}$ around $80 \mathrm{mmHg}$. Twenty-four hours later, the NPPV was attempted to withdraw. First, we gradually decreased the pressure, and then the NPPV was intermittently used eventually to withdraw totally. Successful weaning was defined that the patients maintained spontaneous breathing more than 5 days without any support including NPPV (9).

Reintubation based on generally accepted criteria (one major criterion or at least two minor criteria). Major criterion listed below: respiratory or cardiac arrest, apnea with loss of consciousness, persistent severe hypoxemia $\left(\mathrm{PaO}_{2} / \mathrm{FiO}_{2}<100\right)$ despite non-invasive ventilation (NIV), hemodynamic instability without response to fluids and vasoactive drugs, and persistent inability to remove respiratory secretions (10-12). Minor criterion listed below: $\mathrm{RR} \geq 30$ breaths/min, respiratory acidosis with $\mathrm{pH}<7.35$ and $\mathrm{PaCO}_{2}>45 \mathrm{mmHg}$, hypoxemia $\left(\mathrm{PaO}_{2} / \mathrm{FiO}_{2}<150\right)$, decreased consciousness, agitation or diaphoresis, clinical signs suggestive of respiratory muscle fatigue (involvement of accessory respiratory muscles, paradoxical abdominal, or retraction of intercostal spaces) (10-12). NPPV was tried if the patient didn't require immediate reintubation. However, the decision was made by their attending physicians.

\section{Retrospective matched group}

We retrospective matched 11 tracheotomy patients with 


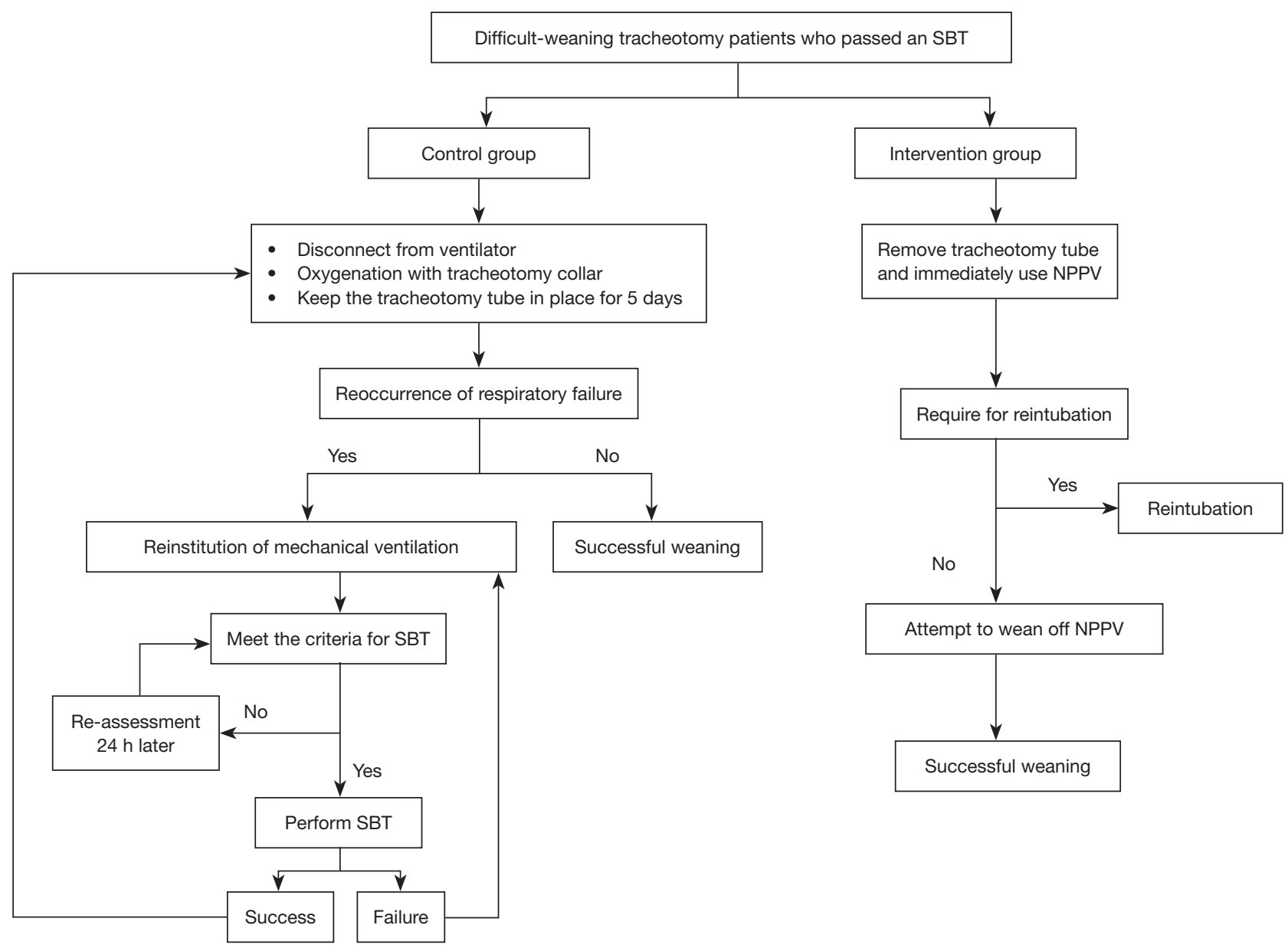

Figure 1 Flow chart of the study. SBT, spontaneous breathing trial; NPPV, noninvasive positive pressure ventilation.

initial SBT success based on the diagnosis, age, gender, and duration of mechanical ventilation. After a patient successfully completed an SBT, the ventilator was disconnected, and oxygenation was administrated through a tracheotomy collar (9). However, the ventilator was re-connected when the respiratory failure reoccurred if the tracheotomy tube was still in place. The criteria for the reinstitution of mechanical ventilation were the same as the criteria for reintubation in the interventional group, but we didn't use NPPV in this period. After the reinstitution of mechanical ventilation, the weaning was also screened every morning (Figure 1). The tracheotomy tube was removed, and the incision was closed if the patient had smooth spontaneous breathing, adequate mental status, effective cough, and secretion controlled (13).

\section{Statistical analysis}

Normal distribution of measurement data was reported as mean \pm standard deviation. Continuous variables were analyzed using group $t$-test (normal distribution) or the Mann-Whitney $U$ test (non-normal distribution) and classification variables using chi-square or Fisher's exact probability method. Difference between the two groups in Kaplan-Meier curves was analyzed by log-rank test. Statistical tests were two-sided and a $\mathrm{P}<0.05$ was considered statistically significant. All data were analyzed by SPSS 18.0 for Windows statistical software.

\section{Results}

Baseline characteristics of two groups at initial SBT success were summarized in Table 1. There was no difference in gender, age, diagnosis, simplified acute physiology scoring II (SAPS II), HR, RR, rapid shallow breathing index, mean arterial pressure, Glasgow coma score (GCS), hemoglobin, days of mechanical ventilation, arterial blood gas analysis, 
Table 1 Baseline characteristics of two groups at initial SBT success

\begin{tabular}{|c|c|c|c|}
\hline Variables & Intervention group $(n=11)$ & Control group $(n=11)$ & $P$ value \\
\hline Age, years (mean \pm SD) & $57.8 \pm 17.5$ & $57.5 \pm 17.2$ & 0.92 \\
\hline \multicolumn{4}{|l|}{ Diagnosis } \\
\hline Sepsis & 1 & 3 & 0.59 \\
\hline AECOPD & 1 & 1 & $>0.99$ \\
\hline ARDS & 1 & 0 & $>0.99$ \\
\hline Severe acute pancreatitis & 2 & 2 & $>0.99$ \\
\hline Trauma & 1 & 0 & $>0.99$ \\
\hline Heart rate, beats/min (mean $\pm \mathrm{SD}$ ) & $96 \pm 16$ & $106 \pm 11$ & 0.08 \\
\hline Mean artery pressure, $\mathrm{mmHg}($ mean $\pm \mathrm{SD})$ & $86 \pm 13$ & $86 \pm 13$ & 0.87 \\
\hline GCS, median [range] & $13[12-15]$ & $12[12-15]$ & 0.70 \\
\hline Hemoglobin, g/dL (mean \pm SD) & $9.9 \pm 1.5$ & $9.0 \pm 1.8$ & 0.33 \\
\hline Days of ventilation, median [range] & $19[13-30]$ & $17[9-41]$ & 0.70 \\
\hline Respiratory rate, breaths/min (mean $\pm \mathrm{SD}$ ) & $23 \pm 4$ & $24 \pm 3$ & 0.46 \\
\hline Rapid shallow breathing index, median [range] & $52[33-58]$ & $53[45-60]$ & 0.61 \\
\hline $\mathrm{pH}($ mean $\pm \mathrm{SD})$ & $7.41 \pm 0.05$ & $7.42 \pm 0.06$ & 0.78 \\
\hline
\end{tabular}

SBT, spontaneous breathing trial; SD, standard deviation; AECOPD, acute exacerbation of the chronic obstructive pulmonary disease; ARDS, acute respiratory distress syndrome; SAPS II, simplified acute physiology score; GCS, Glasgow coma score.

and $\mathrm{PaO}_{2} / \mathrm{FiO}_{2}$ ratio.

Table 2 shows the outcomes between the two groups. Patients in the control group had 39 times of reinstitution of mechanical ventilation after initial SBT success. Compared with control group, the interventional group had fewer weaning days $(3.0 \pm 2.1$ vs. $11.3 \pm 9.2, \mathrm{P}=0.01)$ from initial SBT success to successful weaning and shorter ICU length of stay $(11.6 \pm 4.2$ vs. $20.3 \pm 11.6, \mathrm{P}=0.03)$ after initial SBT success. Moreover, the interventional group had a lower proportion remaining in ICU and a lower proportion remaining in the hospital (Figures 2,3). The interventional group also had less nosocomial pneumonia after initial SBT success, lower ICU mortality, lower hospital mortality, shorter total ICU length of stay, shorter total hospital length of stay, and higher successful weaning rate, but it didn't reach significant difference.

\section{Discussion}

Weaning is a process to improve gas exchange and spontaneous ventilation, gradually decrease ventilator support, and eventually liberate from mechanical ventilation (14). Weaning time accounts for about $40 \%$ of the whole mechanical ventilation time, and the process is likely to be much slower in patients with chronic diseases (15). What's worse, difficult-weaning patients account for $45 \%$ to $57 \%$ in total weaning patients $(16,17)$. And the hospital mortality is $23 \%$ in difficult-weaning patients (17). Thus, improvement 
Table 2 Outcomes between two groups

\begin{tabular}{|c|c|c|c|}
\hline Variables & Intervention group $(\mathrm{n}=11)$ & Control group $(\mathrm{n}=11)$ & $P$ value \\
\hline Reintubation after tracheotomy tube removing & 0 & 0 & $>0.99$ \\
\hline Number of reinstitutions of mechanical ventilation after initial SBT success & 39 & - & - \\
\hline Total ventilation, days & $25.5 \pm 13.3$ & $34.7 \pm 24.2$ & 0.28 \\
\hline Hospital length of stay after initial SBT success, days & $24.0 \pm 22.3$ & $37.4 \pm 31.3$ & 0.26 \\
\hline Total ICU length of stay, days & $35.7 \pm 15.3$ & $45.0 \pm 29.5$ & 0.37 \\
\hline Total hospital length of stay, days & $48.7 \pm 33.1$ & $68.6 \pm 52.6$ & 0.30 \\
\hline Nosocomial pneumonia after initial SBT success & 0 & 2 & 0.48 \\
\hline Hospital mortality & 0 & 3 & 0.24 \\
\hline
\end{tabular}

* $\mathrm{P}<0.05$ was considered statistical significance. SBT, spontaneous breathing trial; ICU, intensive care unit.

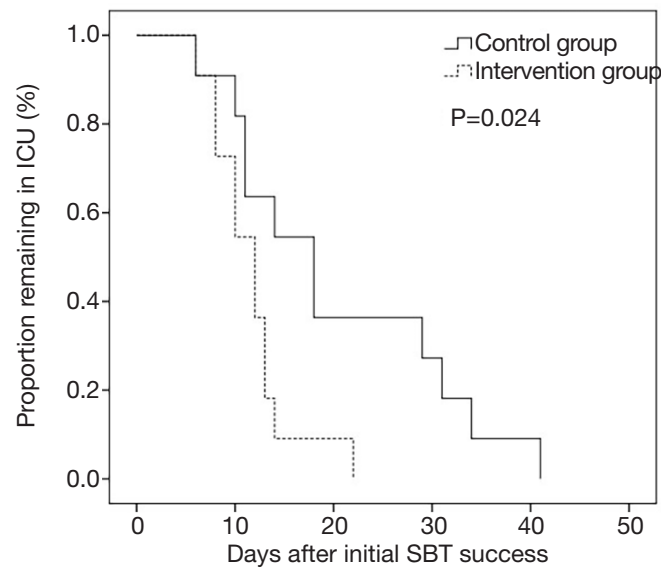

Figure 2 Kaplan-Meier curves for all patients who remained in ICU. ICU, intensive care unit.

of weaning in these difficult-weaning patients is an important issue. Our study provided an alternative weaning method for difficult-weaning tracheotomy patients, which may accelerate the weaning process.

NPPV has been used to wean from invasive mechanical ventilation patients for decades. In patients with an endotracheal tube, prophylactic NPPV reduced reintubation and mortality when it was immediately used if a patient completed an SBT (5-7). However, the value of prophylactic NPPV in weaning off tracheotomy patients is

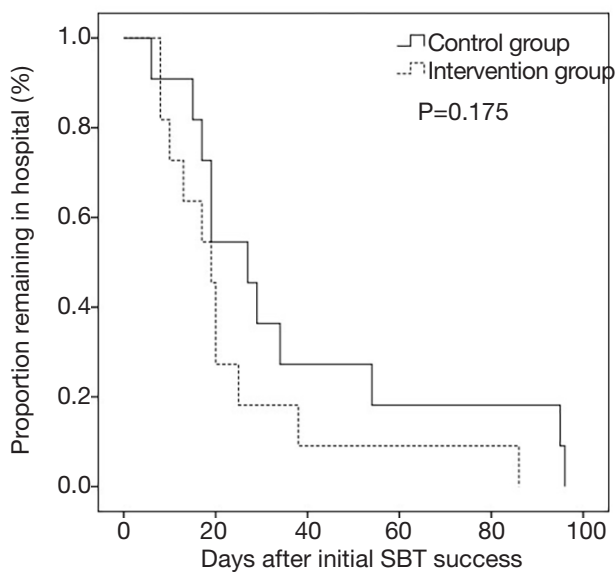

Figure 3 Kaplan-Meier curves for all patients who remained in hospital.

unclear. This study demonstrated that prophylactic NPPV in tracheotomy patient accelerated weaning process. It may be a good choice for difficult-weaning tracheotomy patients.

Different from the endotracheal intubation patients whose upper airway structure was integral, the tracheotomy patients had incision at upper airway, which may decrease the efficacy of NPPV. In this study, we immediately used NPPV after removing the tracheotomy tube when a patient successfully completed an SBT. In addition, to ensure the effectiveness of NPPV, we as far as possible closed the cut 
openings of the trachea with sterile gauze for reducing leakage after removal of tracheotomy tube completely.

A conventional method for weaning off tracheotomy patients was gradual prolonging the unassisted breathing (9). Similar to our study, the conventional weaning patients received unassisted breathing with tracheotomy collar when an SBT completed. If the respiratory failure reoccurred, the mechanical ventilation was reinstituted. However, tracheotomy cutting directly communicates with the atmosphere outside in patients with intermittent weaning. As for the lack of the protection of the glottis and the upper airway, the risk of nosocomial pneumonia increased. In addition, as the tracheotomy tube in place, the narrowed upper airway increased resistance and work of load. These factors may delay weaning in tracheotomy patients.

NPPV as another method for weaning off tracheotomy patients has been reported by Duan et al. (18). In their study, patients' cuff was deflated, tracheotomy tube was capped but still kept in place, and NPPV was used with a face mask. Though this method shortened the weaning process, the tracheotomy tube in place increased airway resistance, which may decrease the efficacy of NPPV. On the contrary, we removed the tracheotomy tube before NPPV. This may maximally improve the efficacy of NPPV.

This study was limited by the small sample size. It just provided the information that the prophylactic NPPV in tracheotomy patients was feasible. To confirm the efficacy of NPPV in tracheotomy patients required to enlarge the sample size. In addition, this is only a matched study. A randomized controlled trial was needed before the general use of this strategy.

\section{Conclusions}

Tracheostomy patients may achieve benefits when the tracheotomy tube is pulled out directly to providing a prophylactic NPPV. It could be helpful in shortening the days of weaning and ICU length of stay.

\section{Acknowledgments}

Funding: None.

\section{Footnote}

Conflicts of Interest: The authors have no conflicts of interest to declare.
Ethical Statement: The authors are accountable for all aspects of the work in ensuring that questions related to the accuracy or integrity of any part of the work are appropriately investigated and resolved. Our institutional review board (West China Hospital, Sichuan University) approved this study (No. 2016-0023). At enrollment, written informed consent was received from the patients or their next of kin.

Open Access Statement: This is an Open Access article distributed in accordance with the Creative Commons Attribution-NonCommercial-NoDerivs 4.0 International License (CC BY-NC-ND 4.0), which permits the noncommercial replication and distribution of the article with the strict proviso that no changes or edits are made and the original work is properly cited (including links to both the formal publication through the relevant DOI and the license). See: https://creativecommons.org/licenses/by-nc-nd/4.0/.

\section{References}

1. El-Khatib MF, Bou-Khalil P. Clinical review: liberation from mechanical ventilation. Crit Care 2008;12:221.

2. Macintyre NR. Evidence-based assessments in the ventilator discontinuation process. Respir Care 2012;57:1611-8.

3. Agarwal R, Aggarwal AN, Gupta D, et al. Role of noninvasive positive-pressure ventilation in postextubation respiratory failure: a meta-analysis. Respir Care 2007;52:1472-9.

4. Esteban A, Alía I, Tobin MJ, et al. Effect of spontaneous breathing trial duration on outcome of attempts to discontinue mechanical ventilation. Spanish Lung Failure Collaborative Group. Am J Respir Crit Care Med 1999;159:512-8.

5. Ferrer M, Valencia M, Nicolas JM, et al. Early noninvasive ventilation averts extubation failure in patients at risk: a randomized trial. Am J Respir Crit Care Med 2006;173:164-70.

6. Ferrer M, Sellarés J, Valencia M, et al. Non-invasive ventilation after extubation in hypercapnic patients with chronic respiratory disorders: randomised controlled trial. Lancet 2009;374:1082-8.

7. Nava S, Gregoretti C, Fanfulla F, et al. Noninvasive ventilation to prevent respiratory failure after extubation in high-risk patients. Crit Care Med 2005;33:2465-70.

8. Funk GC, Anders S, Breyer MK, et al. Incidence and 
outcome of weaning from mechanical ventilation according to new categories. Eur Respir J 2010;35:88-94.

9. Jubran A, Grant BJ, Duffner LA, et al. Effect of pressure support vs unassisted breathing through a tracheostomy collar on weaning duration in patients requiring prolonged mechanical ventilation: a randomized trial. JAMA 2013;309:671-7.

10. Girault C, Bubenheim M, Abroug F, et al. Noninvasive ventilation and weaning in patients with chronic hypercapnic respiratory failure: a randomized multicenter trial. Am J Respir Crit Care Med 2011;184:672-9.

11. Ferrer M, Esquinas A, Arancibia F, et al. Noninvasive ventilation during persistent weaning failure: a randomized controlled trial. Am J Respir Crit Care Med 2003;168:70-6.

12. Boles JM, Bion J, Connors A, et al. Weaning from mechanical ventilation. Eur Respir J 2007;29:1033-56.

13. O'Connor HH, White AC. Tracheostomy decannulation. Respir Care 2010;55:1076-81.

14. MacIntyre NR, Cook DJ, Ely EW Jr, et al. Evidence-

Cite this article as: Liang GP, Zeng YH, Chen BX, Kang Y. Prophylactic noninvasive positive pressure ventilation in the weaning of difficult-weaning tracheotomy patients. Ann Transl Med 2020;8(6):300. doi: 10.21037/atm.2020.02.150 based guidelines for weaning and discontinuing ventilatory support: a collective task force facilitated by the American College of Chest Physicians; the American Association for Respiratory Care; and the American College of Critical Care Medicine. Chest 2001;120:375S-95S.

15. Esteban A, Alía I, Ibañez J, et al. Modes of mechanical ventilation and weaning. A national survey of Spanish hospitals. The Spanish Lung Failure Collaborative Group. Chest 1994;106:1188-93.

16. Peñuelas $\mathrm{O}$, Frutos-Vivar F, Fernández C, et al. Characteristics and outcomes of ventilated patients according to time to liberation from mechanical ventilation. Am J Respir Crit Care Med 2011;184:430-7.

17. Sellares J, Ferrer M, Cano E, et al. Predictors of prolonged weaning and survival during ventilator weaning in a respiratory ICU. Intensive Care Med 2011;37:775-84.

18. Duan J, Guo S, Han X, et al. Dual-mode weaning strategy for difficult-weaning tracheotomy patients: a feasibility study. Anesth Analg 2012;115:597-604. 